\title{
Carcinogenic and non-carcinogenic health risk assessment of air pollutant in a steel industry
}

\author{
AMENEH GOLBAGHI ${ }^{1,2}$, LEILA NEMATPOUR ${ }^{2}$, ZABIHOLAH DAMIRI $^{3}$, BEHZAD FOULADI DEHAGHI $^{1,2,{ }^{*}}$ \\ ${ }^{1}$ Environmental Technologies Research Center, Ahvaz Jundishapur University of Medical Sciences, Ahvaz, Iran. \\ ${ }^{2}$ Department of Occupational Safety and Health Engineering, school of public Health, Ahvaz Jundishapur University of Medical Sciences, \\ Ahvaz, Iran. \\ ${ }^{3}$ Department of Occupational Safety and Health Engineering, school of public Health, Iran University of Medical Sciences, Tehran, Iran. \\ ${ }^{*}$ Correspond author: Behzad Fouladi Dehaghi, tel/fax: +9861337385318, E-mail: bdehaghi@gmail.com
}

\begin{abstract}
Background: Chemical risk assessment is one of the major strategies that can help prioritize hazardous pollutants and decide on appropriate control measures.

Objective: This study aim was evaluating carcinogenic and non-carcinogenic effects of chemical and fume compounds in a steel industry in South Iran.

Methods: This study conducted in one of the steel industry with 1600 workers. After sampling the inhalation air of workers exposed to various chemicals, the method provided by risk assessment information system (RAIS) was used to assess cancer carcinogenic and non-Carcinogenic risk based on the findings.

Results: Asbestos with the content of $1.5 \times 10^{-10}$, chromium $1.36 \times 10^{-2}$, and lead $5.38 \times 10^{-5}$ definitive cancer and definite cancer are in the category of minor cancer effects, respectively. In calculating the non-cancer risk, the risk factor for Quotient Hazard Non-cancer (HQ) in hydrogen sulfide, chromium, and manganese were $3.08 \times 10^{2}$, $5.71 \times 10^{-2}$, and $9.13 \times 10^{2}$ respectively, indicating non-cancer risk in them.

Conclusion: Based on the values provided by the environmental protection agency, it is observed that some pollutants in the steel industry during the study period will increase the risk of cancer and non-cancerous diseases for steel industry workers. Therefore, considering appropriate engineering and management controls can help prevent these effects.

Keywords: Carcinogenic risk, Chemical contaminants, Non-carcinogenic risk.
\end{abstract}

\section{INTRODUCTION}

The steel industry can form the basis and axis of development of industrialized countries. Ranked 15th in the world and first in the Middle East, steel is one of the largest branches of the country's industry with a wide range of production processes. Studies show that operating various high-power equipment in the steel industry can cause environmental hazards. In the steel industry, workers are often exposed to high concentrations of dust particles when working with raw materials such as ores and metal foams ${ }^{1}$. It is significant to control this huge volume of environmental pollutants as dust produced by mining activities has detrimental effects on the environment, human health, safety, and productivity 2,3 . This type of dust may contain hazardous substances such as free silica in the form of coagulation, the constant exposure of which causes irreversible occupational diseases, such as silicosis or silica-induced lung fibrosis 4,5 . Silica dust reduces the ability of rapeseed to absorb oxygen from the air by damaging repo tissues 6 . Studies show a link between dust exposure and pulmonary fibrosis, cancer, and decreased respiratory capacity. Other studies have also shown that long-term use of crystalline free silica increases the risk of lung cancer in exposed workers ${ }^{7-9}$. Toluene is one of the hydrocarbons released in various processes, such as casting, rolling, and coking furnaces in the steel industry 10,11 . The presence of this type of pollutant in the working environment can create a toxic atmosphere that causes many diseases and cancers. Toluene is an aromatic compound with a benzene ring classified by the International Agency for Research on Cancer (IARC) in the A4 group of chemicals ${ }^{12}$. The effects of toluene exposure are mainly the dysfunction of the central, autonomic, and peripheral nervous systems ${ }^{13}$. In particular, we can mention dysfunction of the parasympathetic nervous system, mucosal membrane stimulation, neo-robotics, neurobehavioral dysfunction, renal tubular dysfunction, teratogen effects, chromosomal effects, menstrual irregularities, abortion ${ }^{14}$.To analyze the double cap in the laboratory of the Steel reclamation unit, the personnel is exposed to various chemicals such as nitric acid, hydrogen chloride, sulfuric acid, and hydrogen disulfide. If the precautionary principles and control measures are not followed in these chemicals, working with them can cause several detriments to human health. The extent of these side effects depends on the type of chemical, its characteristics, the route of contact, and the duration of exposure. The purpose of this study is to identify and evaluate the most important risks caused by workers' exposure to some chemicals in this regard. Over the years, risk assessment has grown significantly, and there have been extensive efforts to standardize the process. The study of environmental risk assessment in a Steel factory indicated that the activities of ingot furnace, lathe, and cutting, peeling and shelf assembly are considered a critical environmental risk 15,16 . Also, another study in a Steel industry introduced the iron oxide sludge storage tank with the highest environmental risk due to the activity of this industrial unit ${ }^{16}$. A study of Chinese steelworkers working in a foundry unit reported a very high incidence of cancer risk ${ }^{17}$. In the steel and foundry industries, exposure to hazardous chemicals is one of the most major hazards for workers. To observe the precautionary principles and effective control measures, it is necessary to have a correct assessment of the process of all people in the industry. Therefore, the present study aimed to identify and evaluate 
the most important risks due to workers' exposure to some chemicals, which are due to steelmaking operations, and the results help to provide solutions to reduce their risk. For this purpose, after identifying the steelmaking process, the resulting risks, which include contact with chemicals from drilling mud, are identified by including the amount of pathogenicity and carcinogenic risk in the relevant formula. The Risk Assessment Information System (RAIS), a subsidiary of the US Environmental Protection Agency (EPA), can be used to assess the cancer risk and noncancer risks of various chemicals. It is a tool to provide information on the toxicity of substances to calculate the risk assessment and compare the estimated hazards of those substances with standard values. RAIS has become one of the top Internet risk tools and a real-time calculation engine for environmental chemical and radiological risk assessment in the United States due to its initial focus on fully transparent standards and reference information. In addition to providing background data such as toxicity, chemical properties, and default information on toxin exposure, RAIS provides an integrated tool for calculating environmental risk assessment 18,19 . The results of this study may provide some insight into chemical and fume contaminations in ambient air and are useful for workers to done protective procedures and occupational health in reducing the contaminations of air, and also may be useful as a basis for comparison to other areas both in Iran and worldwide.

\section{METHODS}

This cross-sectional analytical study was conducted in one of the steel companies in the south of Iran. 1600 people working in different specialties, 3500 people are indirectly covered by contractors, who are about 500 people in each shiftwork. RAIS is a web-based system used to spread risk tools and provide information for risk assessment activities. Using searchable and executable databases, displaying data through menus, and loading data using the latest web technologies, RAIS provides the necessary tools and information for the risk assessment process and can be tailored to the needs of the site. Using the information and tools available in RAIS, it is possible to create a conceptual site model, determine appropriate targets for screening and comparison, identify and select potentially concerning chemicals, and extract information to assess toxicity, calculate hazards, and document risk assessment report. The steps for assessing a risk information system (RAIS) are as follows ${ }^{19}$.

I. Determining the objectives of risk assessment: In this stage, the objectives of risk assessment are determined and in accordance with the objective set, the risk assessment criteria, how to calculate and present them.

II. Complete familiarity with the unit under study: complete identification of the unit is achieved by collecting and studying all the required information, which information generally includes identification of the operational process, physical and chemical properties of the materials in the process, etc. Information about the person's history, duration of exposure and frequency of exposure is also specified.
III. Identify the risks: Identifying the risks is very important, because ignoring them means not assessing the risks of those risks.

IV. Sampling materials: after identifying contaminants in the operation according to sampling methods provided by $\mathrm{NIOSH}$, chemicals are sampled and their laboratory analysis is performed 20, 21.

A: Sampling and analysis of Asbestos: For sampling according to NIOSH 7400 standard, sampling using stress cellulose mixed membrane filter (MCE) with sampling circuit included cyclone and holder of individual sampling pump and flexible tubes. Samples were analyzed using contrast phase electron microscopy (PCM).

B: Sampling and analysis of Fume: For sampling according to $7300 \mathrm{NIOSH}$ standard sampling using stress cellulose mixed membrane filter (MCE) with sampling circuit included cyclone and holder of individual sampling pump with a die of $100 \mathrm{ml} \mathrm{p} / \mathrm{min}$ was used and flexible tubes. Samples were analyzed using Atomic absorption spectroscopy (AAS).

C: Sampling and analysis of Toluene: For sampling according to $2549 \mathrm{NIOSH}$ standard Activated carbon pipes with an outer diameter of $6 \mathrm{~mm}$ and an inner diameter of 4 $\mathrm{mm}$ and a length of $7 \mathrm{~cm}$ were used. To collect samples, a sampling pump with a die of $100 \mathrm{ml} \mathrm{p} / \mathrm{min}$ was used. The concentration was analyzed using a gas chromatographic device equipped with an ion- flame detector.

D: Free silica sampling and analysis: For sampling according to NIOSH7500 standard samples were taken using polyvinyl chloride (PVC) filter with a flow rate of 1700 $\mathrm{ml} / \mathrm{min}$. The sampling circuit included cyclone and holder, insurance, individual sampling and flexible tubing. The samples were analyzed using spectrophotometry.

E: Sampling and analysis of hydrochloric acid (HCL): For sampling according to NIOSH 7907 standard, Glass silica gel tubes with an outer diameter of $7 \mathrm{~mm}$ and a length of $11 \mathrm{~cm}$ were used. Sampling pump (SKC) with a flow rate of $500 \mathrm{ml} /$ min was used to collect samples, then the concentrations were analyzed using a chromatographic ion device equipped with a thermal conductivity detector.

F: Sampling and analysis of Nitric acid ( $\mathrm{HNO}_{3}$ ): For sampling according to NIOSH 7903, a silica gel glass tube with an outer diameter of $7 \mathrm{~mm}$ and a length of $11 \mathrm{~cm}$ was used. An individual sampling pump with a flow rate of 200 $\mathrm{ml} / \mathrm{min}$ was used to collect samples. Then the concentration was analyzed using a chromatographic ion device equipped with a thermal conductivity detector.

G: Sampling and analysis of Sulfuric acid $\left(\mathrm{H}_{2} \mathrm{SO}_{4}\right)$ : For sampling according to NIOSH 7401, a silica gel glass tube with an outer diameter of $7 \mathrm{~mm}$ and a length of $11 \mathrm{~cm}$ was used. An individual sampling pump with a flow rate of 1000 $\mathrm{ml} / \mathrm{min}$ was used to collect samples. Then concentration analysis using ion separation chromatography apparatus Equipped with a heat detector (HPLC-AG4A).

$H$ : Sampling and analysis of Hydrogen sulfide $\left(\mathrm{H}_{2} \mathrm{~S}\right)$ : For sampling according to $\mathrm{NIOSH} 6013$ activated carbon pipes, glass with external diameter of $8 \mathrm{~mm}$ and internal diameter of $6 \mathrm{~mm}$ and length of $10 \mathrm{~cm}$ were used. Then concentration analysis was performed using ion-equipped chromatographic device $\mathrm{B}$ and thermal conductivity detector. 
I. Scenario determination: The scenario of the evaluated group (including workers in or outside the composite industry worker, farmer, etc.) should be determined. Also, the exposure environment of people including soil, water, air, fish and the type of chronic and sub-chronic exposure should be specified.

II. Enter data into online risk assessment software:

Entering the collected information to the RAIS site and analyzing the data

The method provided by RAIS is used to assess the cancer risk and non-cancer risk, the data measured by the respiration of employed workers by type of pollutants..

Calculation of carcinogenic risk: Carcinogenic risk was calculated via the following formula. The acceptable carcinogenic risk level set by the EPA for occupations is less than 4 _10.

$\mathrm{ELCR}=\mathrm{ADI} \times \mathrm{CSF}$

ELCR $=$ Excess Lifetime Cancer Risk

$\mathrm{CDI}=$ Chronic Daily Average (Average daily intake through direct breathing)

$\mathrm{CSF}=$ Cancer Slope Factor (Cancer slope factor through inhalation)

Calculation of non-carcinogenic risk: In the next step, the amount of non-risk cancer was calculated using the following equation. To assess noncancerous risks, the $\mathrm{HI}$ risk index and the $\mathrm{HQ}$ risk ratio were examined. Risk assessment is calculated via the oral $\mathrm{HQ}$ index for swallowing, the Dermal $H Q$ for skin contact, and the $H Q$ pencil for inhaling all chemicals, including air pollutants. Here, $\mathrm{HQ}$ is calculated for respiration only. Also, chronic exposure of people to the studied chemicals has been used. Then, the average life expectancy (LT), frequency of exposure per person per day per year (EF), number of hours of exposure to the contaminant per day (ET) and duration of exposure (ED) are recorded in the site 22 .

Quotient Hazard Non-cancer (HQ) =ADI / RFC

In this equation, RFC is equal to the reference value (mg/kg-day) as determined by EPA US.

\section{RESULTS}

Table 1 presents the individual exposure to chemical compounds in milligrams per cubic meter, PPM, and in asbestos fibers with fiber per unit volume in different sections of reduction, control, production, furnace, laboratory, and molding. As shown in Table 1, the pollutants studied are the values of the density in the respiratory air in the production, molding, resuscitation, control and laboratory sections below the allowable occupational exposure limits. Cancer risk assessment and non-cancer risk Chemical contaminants and metal fumes: The highest amount of cancer risk index is related to asbestos. Chromium and lead metals are the second and third highest cancer risk, respectively. In order to analyze the cancer risk, if the risk number is greater than the $1 \times 10^{-4}$ cancer risk is definite (Definite Risk). If the risk number is between $1 \times 10^{-4}$ and $1 \times 10^{-5}$, the risk of cancer is probable (Probable Risk). If it is between $11 \times 10^{-5}$ and $1 \times 10^{-6}$, the risk of cancer is possible (possible risk). And if it is less than $1 \times 10^{-6}$, the risk of cancer is negligible (Negligible Risk). Also, if the concentration of a toxic substance in the air is higher than the reference concentration (the concentration known as the boundary between safety and harm), the $\mathrm{HQ}$ value is more than lindicating the possibility of noncancerous risks ${ }^{23}$. In analyzing the results of risk assessment in Table 2, the concentration of $\mathrm{HQ}$ in chromium and manganese fumes was $5.71 \times 10^{+1}$ and $9.13 \times 10^{+2}$, respectively. This indicates a non-cancerous risk in chromium and manganese. Although, in other pollutants, these values were less than recommended at risk of cancer, chromium with a rate of $1.36 \times 10^{-2}$ is in the definitive category of cancer. Also, lead at the rate of $5.38 \times 10^{-5}$ is in the category of possible cancer. Cancer risk has not been observed in other metal contaminants. Chronic daily inhalation rate (CDI) compared to health guidelines indicates that this value is comparable to the reference concentration (RFC). As shown in Table 2, aluminum has a daily absorbance of cancer 1.63 and was higher than the reference concentration. In chromium pollutants, it is observed that the daily absorption of cancerous and non-cancerous inhalations is, respectively $1.63 \times 10^{-1}$ and $4.57 \times 10^{-4}$ were higher than the reference concentration. Also, manganese or the amount of $1.63 \times 10^{-}$ 1 . In the daily absorption of cancer inhalation and a value of $4.57 \times 10^{-2}$ in the daily absorption of non-cancerous inhalation was observed more than the reference concentration. Table 3 calculates the carcinogenic risk and non-cancerous risk of respiratory exposure to chemical contaminants. In calculating the non-cancer risk, the risk factor of $\mathrm{HQ}$ in hydrogen chloride, hydrogen sulfide, silica, sulfuric acid, and toluene were $5.14 \times 10^{-2}, 3.08 \times 10^{-2}$, $3.42 \times 10^{-1}, 2.05 \times 10^{-1}$, and $9.62 \times 10^{-2}$ respectively. If the $\mathrm{HQ}$ level exceeds threshold number one, there is a possibility of damage to health, which indicates the high noncancerous risks of hydrogen sulfide in all samples. As can be seen in Table 3 the amount of cancer risk in asbestos with a density of $1.5 \times 10^{-10}$, which is in the category of cancer risk is low, but in other pollutants, cancer risk has not been observed. Also, the two pollutants were carbon monoxide and nitric acid without any cancer risk and noncancer risk. As shown in Table 3 , the daily uptake for carcinogenic inhalation of asbestos pollutants was $6.52 \times 10^{-}$ ${ }^{4} \mathrm{\mu g} / \mathrm{m}^{3}$, but it was $1.83 \times 10^{-3} \mathrm{mg} / \mathrm{m}^{3}$ for non-cancerous inhalation. Also, the daily absorption rate for inhalation of carcinogens in hydrogen sulfide was $3.42 \mathrm{E}+00 \mu \mathrm{g} / \mathrm{m}^{3}$ and for non-cancerous substances were $9.59 \times 10^{-3} \mathrm{mg} / \mathrm{m} 3$. In nitric acid, the daily absorption for cancerous inhalation was $1.06 \mu \mathrm{g} / \mathrm{m}^{3}$, and non-cancerous was $2.97 \times 10^{-3} \mathrm{mg} / \mathrm{m}^{3}$, which was seen in these samples without reference value. Hydrogen chloride, with a daily absorption rate of $6.07 \times 10^{-1}$ $\mu \mathrm{g} / \mathrm{m} 3$, is greater than the reference concentration value. Also, in hydrogen sulfide, the daily absorption of cancerous and non-cancerous inhalations was equal to $2.2 \mu \mathrm{g} / \mathrm{m}^{3}$ and $6.16 \times 10^{-3} \mathrm{mg} / \mathrm{m} 3$ which in both cases was higher than the RFC value. Silica is with a dose of $5 \mathrm{mg} / \mathrm{m} 3$ in the daily absorption rate of non-cancerous inhalation, which is higher than the amount of RFC, and in sulfuric acid with a rate of $7.34 \times 10^{-2} \mathrm{\mu g} / \mathrm{m}^{3}$ Cancer inhalation were higher than RFC. Toluene was lower than RFC in the daily absorption rates of cancer and non-cancer inhalers. Tables 4 and 5 show the cancer risk of metal fumes and chemical contaminants as a percentage. The results of cancer risk assessment showed that the highest cancer risk is related to asbestos with full risk percentage and then chromium 
with 99.61 risk percentage. Manganese with $94.03 \%$ and $0.09 \%$ aluminum with the highest and lowest non-cancer risk, respectively.

\section{DISCUSSION}

The present study aimed to evaluate the cancer risk and non-cancer risk of chemicals in one of the steel industries based on RAIS software the guidelines of the US Environmental Protection Agency. Risk assessment is a process of estimating the adverse effects on health and consequent exposure to chemical contaminants. The results of the study of respiratory exposure (Table 1) showed that the exposure of iron, manganese, and lead in exposed workers is more than the allowable threshold. Also, the emission of inhaled pollutants is high in the furnace unit and other pollutants including asbestos (hydrogen sulfide, hydrogen chloride, nitric acid, sulfuric acid, silica, toluene, aluminum, and chromium) with low exposure. Despite this, asbestos carries the highest risk of cancer. According to the International Agency for Research on Cancer (IARC), asbestos is known to be a definitive human carcinogen, causing many occupational diseases in many organs of the body, such as lung (asbestosis or lung fibrosis), skin (asbestos blisters), and nervous system disorders ${ }^{24}$. The results of this study show that hydrogen sulfide has the highest non-cancer risk. According to $A C G I H$ and IARC, it is in carcinogenic group A3 and group $2 \mathrm{~B}$.

Given that $81 / 6 \%$ of hydrogen sulfide is at high risk, it can be detrimental to people exposed to it if left unchecked in the air, which can lead to respiratory upper tract irritation, central nervous system disorders, and other complications 25,26 . In the present study, the exposure rate of daily absorption of cancerous and non-cancerous inhalation with mist chromium was $1.63 \times 10^{-1}$ and $4.57 \times 10^{-4}$ respectively, higher than the reference concentration, and the rate of occupational exposure to respiratory was lower than the standard. Contact with chromium can cause occupational dermatitis. Among occupational allergic dermatitis, they cover $6 / 5 \%$ of chromium contact ${ }^{27}$. Proctor et al. (2016) examined the non-cancer risk in occupational exposure to hexavalent chromium in plating. They demonstrated that the level of respiratory exposure to hexavalent chromium was lower than the occupational limit but the level of noncarcinogenic risk was higher than acceptable ${ }^{28}$, which is consistent with the present study. Gholami et al., assessed the risk of welders' exposure to gases and metal fumes in the shipbuilding industry. They showed that the average concentration of exposure to carbon monoxide and the metals manganese and chromium was above the occupational limit by the American Association of Industrial Health Professionals (ACGIH) ${ }^{29,30}$. The risk rating of high carbon monoxide $(\mathrm{H})$ is high and manganese has the highest risk rating $(\mathrm{VH})$ in metals, which is consistent with the present study. In addition, in this study, the daily noncancerous inhalation absorption rate of silica was $5 \mathrm{mg} /$ $\mathrm{m}^{3}$, which is higher than the $\mathrm{RfC}$ rate. Exposure to dust caused by silica particles endangers the health of exposed workers. Exposure to silica increases the risk of tuberculosis and lung disease. The rate of decline in pulmonary function of working people in the face of silica dust is high. Shojaee Borjoui et al., examined the monitoring and evaluation of the health hazards of respiratory exposure to dust, showing that the results Workers' average exposure to inhalable dust and crystalline silica were $4.46 \pm 1.34 \mathrm{mg} / \mathrm{m}^{3}$ and $0.57 \pm 0.10$ $\mathrm{mg} / \mathrm{m}^{3}$ respectively. $\mathrm{HQ}$ values were higher than the allowable level, requiring the prioritization of serious control measures to reduce risk. The results of the cancer risk assessment showed that all people are in the low-risk range for cancer and are acceptable risk cancer because the numerical values of the risk obtained are less than $10^{-6}$ 31 . The highest respiratory exposure to crystalline silica was measured in the molding section, which can be attributed to the type of task and their work environment. Rashnuodi et al. (2020) examined the risk of exposure to chemical pollutants (benzene, toluene, ethyl benzene, and xylene) in the petrochemical industry. They showed that the risk rating of benzene had a high-risk level, ethyl benzene and xylene have a medium risk rating and toluene has a lowrisk level ${ }^{32}$. Omidi et al., evaluated the carcinogenic and non-carcinogenic risks of exposure to volatile organic compounds in the steel industry. The amount of noncarcinogenic risk ( $\mathrm{HQ})$ of benzene, toluene, ethyl benzene, and xylene in all cases is less than one and the carcinogenic risk of benzene is higher than the maximum acceptable value 33 . The results of both recent studies are consistent with the current study.

\section{CONCLUSION}

The findings of the present study showed that chromium has definite cancer and lead has possible cancer and asbestos has a low risk. Due to the high concentration of iron, manganese, and lead pollutants above the allowable limit, by replacing the less hazardous material, engineering measures and management measures can significantly reduce the risk of the desired pollutant. Also, effective training programs can play an important role in reducing health risks and implementing control measures.

Acknowledgments: We thanks all the participants in this study and Ahvaz Jundishapur University of Medical Sciences (IR.AJUMS.REC.1399.916).

Competing interests: The authors declare that they have no conflicts of interest.

\section{REFERENCES}

1 Qing X, Yutong Z, Shenggao L. Assessment of heavy metal pollution and human health risk in urban soils of steel industrial city (Anshan), Liaoning, Northeast China. Ecotoxicology and environmental safety. 2015;120:377-85.

2 Wang L, K., Pereira N, C., Hung Y-T. Advanced air and noise pollution control: Springer; 2005.2005.

3 Mohammadi AA, Zarei A, Maiidi S, Ghaderpoury A, Hashempour $\mathrm{Y}$, Saghi $\mathrm{MH}$, et al. Carcinogenic and noncarcinogenic health risk assessment of heavy metals in drinking water of Khorramabad, Iran. MethodsX. 2019;6:1642-51.

4 Caruso C, C. . Silicosis; learn the facts. 2004.2004.

5 National Inst. for Occupational Safety and Health $\mathrm{C}, \mathrm{OH}$. $\mathrm{NIOSH}$ Alert Request for Assistance in Preventing Silicosis and Deaths in Construction Workers. 1996. 1996.

6 Naghizadeh A, Mahvi A, Jabbari H, Dadpour4 A, karimi M. Determination the Level of Dust ond Free Silica in Air of Khaf Iron Stone Quarries. Iranian Journal of Health and Environment. 2008;1(1):37-44. 
7 Chu C, Marks JG, Flamm A. Occupational Contact Dermatitis: Common Occupational Allergens. Dermatologic Clinics. 2020;38(3):339-49.

8 Finkelstein MM. Silica, silicosis, and lung cancer: a risk assessment. American journal of industrial medicine. 2000;38(1):8-18.

9 Christiani DC. Occupational Exposures and Lung Cancer. Am J Respir Crit Care Med. 2020;202(3):317-9.

10. Wu X, Zhao L, Zhang $Y$, Zheng C, Gao X, Cen K. Primary Air Pollutant Emissions and Future Prediction of Iron and Steel Industry in China. Aerosol and Air Quality Research. 2015;15.

$11 \mathrm{Gu} \mathrm{Y,} \mathrm{Xu} \mathrm{J,} \mathrm{Keller} \mathrm{A,} \mathrm{Yuan} \mathrm{D,} \mathrm{Li} \mathrm{Y,} \mathrm{Zhang} \mathrm{B,} \mathrm{et} \mathrm{al.}$ Calculation of water footprint of the iron and steel industry: a case study in Eastern China. Journal of Cleaner Production. 2015;92:274-81.

12 Hygienists. ACoGI. TLVs ${ }^{\circledR}$ and BEls®: Threshold Limit Values for Chemical Substances and Physical Agents and Biological Exposure Indices.2015

13 Win-Shwe TT, Fujimaki $H$. Neurotoxicity of toluene. Toxicology letters. 2010;198(2):93-9.

14 Klaassen CD. Casarett and Doull's toxicology: the basic science of poisons: McGraw-Hill New York; 2013.

15 Jozi SA, Majd NM. Health, safety, and environmental risk assessment of steel production complex in central Iran using TOPSIS. Environmental monitoring and assessment. 2014;186(10):6969-83.

16 Olua V, Patrick-Iwuanyanwu K, Nwaichi E. Heavy Metals Contents and Health Risk Assessment of Classroom Corner Dusts in Selected Public Primary Schools in Rivers State, Nigeria. Journal of Environment Pollution and Human Health. 2018;6:138-47.

17 Jin R, Chen Q. Safety culture: effects of environment, behavior \& person. Professional safety. 2013;58:60-70.

18 Dolislager F, Galloway L, Stewart D. The Risk Assessment Information System (RAIS): Insights from the Evolution of an Online Region-Specific Tool to and International Environmental Risk Assessment Center. ENVIRONMENTAL SOFTWARE SYSTEMS. 2014

19 UnitedStatesDepartmentofEnergy. The risk assessment information system (USDOE). Oak Ridge, TN: US Department of Energy's Oak Ridge Operations Office (ORO),. 2011 Available at: https://rais.ornl.gov/.

20. Eller P. NIOSH Manual of Analytical Methods) Hydrocarbons. Halogenated (: Diane Publishing Company. 1994:2003-154.

21 ISO I. 14966: Ambient air-Determination of numerical concentration of inorganic fibrous particles--Scanning electron microscopy method. International Organization for Standardization. 2002.
22 Leung $\mathrm{AO}$, Duzgoren-Aydin NS, Cheung $\mathrm{K}$, Wong $\mathrm{MH}$. Heavy metals concentrations of surface dust from e-waste recycling and its human health implications in southeast China. Environmental science \& technology. 2008;42(7):2674-80.

23 Zhang Z, Yan X, Gao F, Thai P, Wang H, Chen D, et al. Emission and health risk assessment of volatile organic compounds in various processes of a petroleum refinery in the Pearl River Delta, China. Environmental Pollution. 2018;238:452-61.

24 Humans IWGotEoCRt. Arsenic, metals, fibres, and dusts. IARC Monogr Eval Carcinog Risks Hum. 2012;100(Pt C):11465.

25 Zhang Y, Zeng W, Li Y. Computational study of surface orientation effect of rutile $\mathrm{TiO} 2$ on $\mathrm{H} 2 \mathrm{~S}$ and $\mathrm{CO}$ sensing mechanism. Applied Surface Science. 2019;495:143619.

26. Mallon W. Occupational exposure limits. Occupational Health Southern Africa. . 2016;22(5)

27 Chu C, Marks JG, Jr., Flamm A. Occupational Contact Dermatitis: Common Occupational Allergens. Dermatol Clin. 2020;38(3):339-49.

28 Proctor DM, Suh M, Mittal L, Hirsch S, Valdes Salgado R, Bartlett $\mathrm{C}$, et al. Inhalation cancer risk assessment of hexavalent chromium based on updated mortality for Painesville chromate production workers. J Expo Sci Environ Epidemiol. 2016;26(2):224-31.

29 Mehrifar Y, Mohebian Z, Bidel H. Exploring the risk of welders' exposure to the gases and metal fumes in a shipbuilding industry: a case study. Journal of Health and Safety at Work. 2020;10(2):129-37.

30 Gholami A, Sajedifar J, Dehaghi BF, Gavamabadi LI, Boghsani GT, Tazeroudi A, et al. Lung function and respiratory symptoms among mine workers in the Eastern part of Iran. Russian Open Medical Journal. 2018;7(3).

31 Shojaee Barjoee S, Azimzadeh $\mathrm{H}$, MoslehArani A, K, MohamadReza. Occupational monitoring and health risks assessment of respiratory exposure to dust in an industrial unit of production Khak-e-Chini. Occupational Medicine Quarterly Journal. 2019;11(3):14-25.

32 Rashnuodi P, Dehaghi BF, Rangkooy HA, Amiri A, Mohi Poor S. Evaluation of airborne exposure to volatile organic compounds of benzene, toluene, xylene, and ethylbenzene and its relationship to biological contact index in the workers of a petrochemical plant in the west of Iran. Environmental Monitoring and Assessment. 2021;193(2):94.

33 Omidi F, Fallahzadeh RA, Dehghani F, Harati B, Barati Chamgordani S, Gharibi V. Carcinogenic and noncarcinogenic risk assessment of exposure to volatile organic compounds (BTEX) using Monte-Carlo simulation technique in a steel industry. Journal of Health and Safety at Work. 2018;8(3):299-308.

Table1. Concentration of chemical compounds in the respiratory tract of employees in terms of $\mathrm{mg} / \mathrm{m}^{3}$

\begin{tabular}{|l|l|l|l|l|}
\hline & Exposure Rate & TWA & Work area & Number of workers \\
\hline Asbestos & 0.008 & 0.1 & Production line \\
\hline Silica & 0.005 & 6 & Molding & 300 \\
\hline $\mathrm{Co}$ & 3 & 28.64 & Direct Reduction Process (DRP) \\
\hline $\mathrm{HCL}$ & 0.007 & 2.98 & Laboratory & 300 \\
\hline $\mathrm{H} 2 \mathrm{~S}$ & 0.004 & 1.4 & Control & 200 \\
\hline $\mathrm{HNO} 3$ & 0.033 & 5.15 & Laboratory & 100 \\
\hline $\mathrm{H} 2 \mathrm{SO} 4$ & 0.001 & 0.2 & Laboratory & 300 \\
\hline $\mathrm{Toluene}$ & 8.82 & 75.37 & Laboratory & 100 \\
\hline $\mathrm{AL}$ & 0.02 & 1 & Furnace & 100 \\
\hline $\mathrm{Cr}$ & 0.002 & 0.05 & Furnace & 100 \\
\hline $\mathrm{Fe}$ & 5.23 & 5 & Furnace & 300 \\
\hline $\mathrm{Pb}$ & 0.055 & 0.05 & Furnace & 300 \\
\hline $\mathrm{Mn}$ & 0.2 & 0.01 & Furnace \\
\hline
\end{tabular}


Table2. Results of cancer risk assessment and non-cancerous risks of fume Metal

\begin{tabular}{|c|c|c|c|c|c|c|c|c|c|c|c|c|}
\hline Chemical & $\begin{array}{l}\text { CAS } \\
\text { Number }\end{array}$ & $\begin{array}{l}\text { Mutag } \\
\text { en? }\end{array}$ & $\begin{array}{l}\text { VOC } \\
?\end{array}$ & $\begin{array}{l}\text { IUR } \\
\text { (ug/m3)- } \\
1\end{array}$ & $\begin{array}{l}\text { IUR } \\
\text { Ref }\end{array}$ & $\begin{array}{l}\mathrm{RfC} \\
(\mathrm{mg} / \mathrm{m} 3)\end{array}$ & $\begin{array}{l}\text { RfC } \\
\text { Ref }\end{array}$ & $\begin{array}{l}\text { Air } \\
\text { Concentration } \\
\text { (ug or } \\
\text { fibers } / \mathrm{m} 3 \text { ) }\end{array}$ & $\begin{array}{l}\text { Inhalation } \\
\text { Noncarcinogen } \\
\text { ic } \\
\mathrm{CDI} \\
(\mathrm{mg} / \mathrm{m} 3)\end{array}$ & $\begin{array}{l}\text { Inhalation } \\
\text { Carcinogenic } \\
\text { CDI } \\
\text { (ug/m3) }\end{array}$ & $\begin{array}{l}\text { Inhalation } \\
\mathrm{HQ}\end{array}$ & $\begin{array}{l}\text { Inhalation } \\
\text { Risk }\end{array}$ \\
\hline Aluminum & $7429-90-5$ & No & No & - & & $5.00 \mathrm{E}-03$ & $\mathrm{U}$ & 20 & 4.57E-03 & $1.63 \mathrm{E}+00$ & $9.13 \mathrm{E}-01$ & - \\
\hline $\begin{array}{l}\text { Chromium VI } \\
\text { (chromic acid } \\
\text { mists) }\end{array}$ & $1333-82-0$ & Yes & No & 8.40E-02 & $U$ & 8.00E-06 & U & 2 & 4.57E-04 & 1.63E-01 & $5.71 \mathrm{E}+01$ & 1.36E-02 \\
\hline Iron & $7439-89-6$ & No & No & - & & - & & 5230 & $1.19 \mathrm{E}+00$ & $4.26 \mathrm{E}+02$ & - & - \\
\hline $\begin{array}{l}\text { Lead and } \\
\text { Compounds }\end{array}$ & $7439-92-1$ & No & No & $1.20 \mathrm{E}-05$ & $\mathrm{U}$ & - & & 55 & 1.26E-02 & $4.48 \mathrm{E}+00$ & - & 5.38E-05 \\
\hline $\begin{array}{l}\text { Manganese } \\
\text { (Non-diet) }\end{array}$ & $7439-96-5$ & No & No & - & & $5.00 \mathrm{E}-05$ & $U$ & 200 & 4.57E-02 & $1.63 \mathrm{E}+01$ & $9.13 E+02$ & - \\
\hline *Total Risk/HI & & & & - & & - & & _ & - & - & $9.71 \mathrm{E}+02$ & 1.65E-02 \\
\hline
\end{tabular}

Table3. Results of cancer risk assessment and non-cancerous risks of chemical compounds.

\begin{tabular}{|c|c|c|c|c|c|c|c|c|c|c|c|c|}
\hline Chemical & CAS Number & $\begin{array}{l}\text { Mut } \\
\text { age } \\
\text { n? }\end{array}$ & $\begin{array}{l}\text { VOC } \\
?\end{array}$ & $\begin{array}{l}\text { IUR } \\
\text { (ug/m3)- } \\
1\end{array}$ & $\begin{array}{l}\text { IUR } \\
\text { Ref }\end{array}$ & $\begin{array}{l}\mathrm{RfC} \\
(\mathrm{mg} / \mathrm{m} 3)\end{array}$ & $\begin{array}{l}\text { RfC } \\
\text { Ref }\end{array}$ & $\begin{array}{l}\text { Air } \\
\text { Concentrati } \\
\text { on } \\
\text { (ug or } \\
\text { fibers/m3) }\end{array}$ & $\begin{array}{l}\text { Inhalation } \\
\text { Noncarcinogeni } \\
\text { c } \\
\text { CDI } \\
(\mathrm{mg} / \mathrm{m} 3)\end{array}$ & $\begin{array}{l}\text { Inhalation } \\
\text { Carcinogenic } \\
\text { CDI } \\
\text { (ug/m3) }\end{array}$ & $\begin{array}{l}\text { Inhalation } \\
\mathrm{HQ}\end{array}$ & $\begin{array}{l}\text { Inhalatio } \\
\text { n } \\
\text { Risk }\end{array}$ \\
\hline Asbestos & $1332-21-4$ & No & No & $2.30 \mathrm{E}-07$ & IRIS & - & & 0.008 & $1.83 \mathrm{E}-03$ & $6.52 \mathrm{E}-04$ & - & $1.50 \mathrm{E}-10$ \\
\hline $\begin{array}{l}\text { Carbon } \\
\text { Monoxide }\end{array}$ & $630-08-0$ & No & Yes & - & & - & & 34.3 & $7.83 \mathrm{E}-03$ & $2.80 \mathrm{E}+00$ & - & - \\
\hline $\begin{array}{l}\text { Hydrogen } \\
\text { Chloride }\end{array}$ & $7647-01-0$ & No & Yes & - & & $2.00 \mathrm{E}-02$ & IRIS & 7.45 & $1.70 \mathrm{E}-03$ & 6.07E-01 & $8.50 \mathrm{E}-02$ & - \\
\hline $\begin{array}{l}\text { Hydrogen } \\
\text { Sulfide }\end{array}$ & $7783-06-4$ & No & Yes & - & & $2.00 \mathrm{E}-03$ & IRIS & 42 & $9.59 \mathrm{E}-03$ & $3.42 \mathrm{E}+00$ & $4.79 \mathrm{E}+00$ & - \\
\hline Nitric Acid & $7697-37-2$ & No & Yes & - & & - & & 13 & 2.97E-03 & $1.06 \mathrm{E}+00$ & - & - \\
\hline $\begin{array}{l}\text { Silica } \\
\text { (crystalline, } \\
\text { respirable) }\end{array}$ & $7631-86-9$ & No & No & - & & $3.00 \mathrm{E}-03$ & CALEPA & 5 & $1.14 \mathrm{E}-03$ & $4.08 \mathrm{E}-01$ & 3.81E-01 & - \\
\hline Sulfuric Acid & 7664-93-9 & No & No & - & & $1.00 \mathrm{E}-03$ & CALEPA & 1 & $2.28 \mathrm{E}-04$ & $8.15 \mathrm{E}-02$ & $2.28 \mathrm{E}-01$ & - \\
\hline Toluene & $108-88-3$ & No & Yes & - & & $5.00 \mathrm{E}+00$ & IRIS & 8820 & $2.01 \mathrm{E}+00$ & $7.19 \mathrm{E}+02$ & $4.03 \mathrm{E}-01$ & - \\
\hline${ }^{*}$ Total Risk/HI & & & & - & & - & & - & - & - & $5.89 \mathrm{E}+00$ & $1.50 \mathrm{E}-10$ \\
\hline
\end{tabular}

Table4. Percentage of Inhalation Risk of chemical compound

Table4. Percentage of Inhalation Risk of chemical compound
\begin{tabular}{|l|l|c|}
\hline Chemical & $\begin{array}{l}\text { Inhalation } \\
\text { HQ }\end{array}$ & $\begin{array}{c}\text { Inhalation } \\
\text { Risk }\end{array}$ \\
\hline Asbestos (units in fibers) & - & $100.0 \%$ \\
\hline Carbon Monoxide & - & - \\
\hline Hydrogen Chloride & $1.4 \%$ & - \\
\hline Hydrogen Sulfide & $81.39 \%$ & - \\
\hline Nitric Acid & - & - \\
\hline Silica (crystalline, respirable) & $6.46 \%$ & - \\
\hline Sulfuric Acid & $3.88 \%$ & - \\
\hline Toluene & $6.84 \%$ & - \\
\hline${ }^{*}$ Total Risk/HI & $100.0 \%$ & - \\
\hline
\end{tabular}

Table5. Percentage of Inhalation Risk of chemical compound

\begin{tabular}{l}
\begin{tabular}{|l|l|c|}
\hline Chemical & $\begin{array}{l}\text { Inhalation } \\
\text { HQ }\end{array}$ & $\begin{array}{c}\text { Inhalation } \\
\text { Risk }\end{array}$ \\
\hline Aluminum & $0.09 \%$ & - \\
\hline Chromium VI (chromic acid mists) & $5.88 \%$ & $99.61 \%$ \\
\hline Iron & - & - \\
\hline Lead and Compounds & - & \\
\hline Manganese (Non-diet) & $94.03 \%$ & $0.39 \%$ \\
\hline${ }^{\star} T$ Total Risk/HI & $100.0 \%$ & - \\
\hline
\end{tabular} \\
\hline
\end{tabular}

